\title{
Staged surgery for tandem cervical and lumbar spinal stenosis: Which should be treated first?
}

\author{
Chi-An Luo ${ }^{1}$ Arun-Kumar Kaliya-Perumal ${ }^{1,2} \cdot$ Meng-Ling Lu $^{3} \cdot$ Lih-Huei Chen $^{1} \cdot$ Wen-Jer Chen ${ }^{1,4} \cdot$ Chi-Chien Niu $^{1}$ (i)
}

Received: 27 June 2018 / Revised: 25 September 2018 / Accepted: 12 October 2018 / Published online: 17 October 2018

(c) The Author(s) 2018

\begin{abstract}
Purpose Tandem spinal stenosis (TSS) refers to lumbar and cervical spinal canal stenosis. Staged surgery is often chosen, but sometimes, mere decompression of one stenosis is adequate to relieve symptoms. Therefore, we intend to analyze whether starting with the cervical or the lumbar region is the most logical option.

Methods We retrospectively reviewed the data of 47 patients with TSS, having first-stage decompression for the most symptomatic stenosis, and classified into two groups (Group A: lumbar decompression first, Group B: cervical decompression first). Postoperative outcomes were analyzed for at least 2 years, and they were cautiously watched for symptoms of the non-operated stenosis; if such symptoms were debilitating, second-stage surgery for the non-operated stenosis was done.

Results The demographic characteristics of Group A $(n=11)$ and Group B $(n=36)$ were comparable. One patient $(9 \%)$ in Group A and 25 patients (67\%) in Group B had resolution of symptoms and good functional recovery. The need for a secondstage surgery for the non-operated stenosis was significantly high $(p=0.001)$ among patients in Group A. They suffered a significant worsening of both the mJOA score and the Nurick's grade; whereas, patients in Group B experienced staged improvement of both scales.

Conclusion First-stage surgery for the cervical stenosis significantly lowers the need of the second-stage surgery. In contrast, if lumbar stenosis was treated first, a dramatic exacerbation of the symptoms related to the cervical stenosis can occur soon. Therefore, treatment of cervical stenosis first seems to be more appropriate.
\end{abstract}

Graphical abstract These slides can be retrieved under Electronic Supplementary Material.

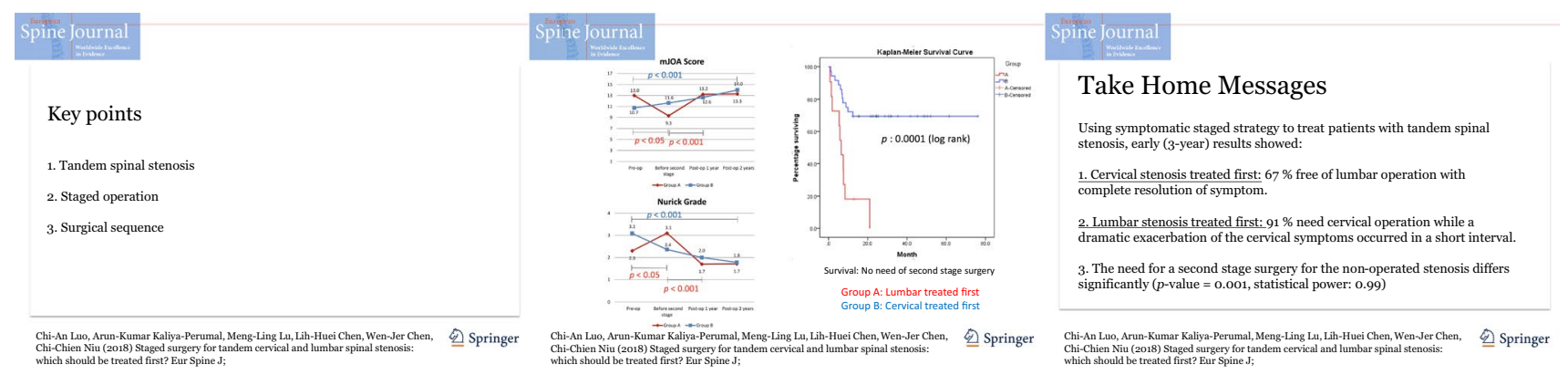

Keywords Tandem spinal stenosis $\cdot$ Spondylosis $\cdot$ Staged operation $\cdot$ Surgical sequence

Electronic supplementary material The online version of this article (https://doi.org/10.1007/s00586-018-5795-6) contains supplementary material, which is available to authorized users.

Chi-Chien Niu

niuchien@adm.cgmh.org.tw

Extended author information available on the last page of the article

\section{Introduction}

Tandem spinal stenosis (TSS) refers to spinal canal stenosis at two different regions of the spine, most commonly involving the lumbar and cervical regions. The condition has a complex clinical presentation that includes signs and symptoms in the 
upper and lower extremities, such as progressive gait abnormality, intermittent neurogenic claudication, mixed myelopathy, and polyradiculopathy [1]. Some factors were found to independently correlate with the diagnosis of concomitant cervical stenosis in patients with radiological evidence of lumbar stenosis. These factors include higher age at presentation, male gender, more levels of radiologically evident degenerative lumbar stenosis, and type III lumbar spinal canal morphology in patients with developmental stenosis [2]. Moreover, isolated single symptomatic cervical or lumbar stenosis is more frequently encountered than coexisting symptomatic cervical and lumbar stenosis [3, 4].

Identification of symptomatic TSS is paramount in the management of these patients [5]. Even though one of the tandem stenoses can be an incidental radiological finding without causing symptoms, its potential to become symptomatic cannot be ruled out [6]. Timely surgical intervention can effectively relieve symptomatic TSS [1]. Staged surgery is often preferred over single-stage surgery due to its lower risk among elderly patients [7]. As to prioritizing the management of cervical versus lumbar stenosis, Aydogen et al. [8] and Dagi et al. [1] advocate treating the most symptomatic stenosis first; however, this is usually based on the surgeon's discretion.

Surgical management of the most symptomatic stenosis and conservative management of the other stenosis are viable options, and this avoids the risk of a second-stage surgery. Although the severity of stenosis in one region may mask the symptoms of the other stenosis [1, 3, 9], surgical decompression of the most significant stenosis can sometimes alleviate the majority of the symptoms $[10,11]$. There are reports where treatment of the cervical stenosis resulted in an improvement of lumbar symptoms, with dramatic decrease or complete resolution of leg pain and sensory deficits $[5,7,10-12]$.

Considering that no consensus currently exists, probably due to the difficulties in identifying the most symptomatic stenosis and the potential for the disease to progress postoperatively, there is need for further research as to the best management of TSS. Which stenosis to treat first, and whether treatment of one stenosis is adequate to relieve symptoms, is still debatable.

Thus, the purpose of this retrospective study was to evaluate if decompression of the cervical or lumbar stenosis alone is adequate to relieve symptoms of TSS and to analyze the progression of symptoms of the non-operated stenosis.

\section{Methods}

We hypothesized that surgery for either cervical or lumbar stenosis is adequate to relieve the symptoms of TSS. After Institutional Review Board approval, the records of patients with TSS who underwent spinal decompression surgery from January 1, 2010 to December 31, 2015 were retrospectively reviewed. Those patients with incomplete records, diagnosis of developmental spinal stenosis, spinal cord dysfunction due to a spinal tumor, infection, fracture, or multiple sclerosis were excluded.

Diagnosis of TSS required compatible clinical and radiological evaluations. Clinical evaluation included complete neurological examination, functional assessment using the modified Japanese Orthopaedic Association (mJOA) score, a 17-point scoring system to assess physical ability [13], and Nurick's myelopathy grading, which is based on ambulatory status [14]. Radiological evaluation consisted of whole spine magnetic resonance imaging (MRI) to identify pathologies at multiple levels.

We adopted the stenosis grading systems proposed by Kang et al. [15] and Lee et al. [16] using cervical T2-weighted sagittal images and lumbar T2-weighted axial images, respectively. Both grading systems have moderate to excellent reliability and have been widely used for clinical studies [3, 17]. MRI of the brain and other investigations (cerebrospinal fluid analysis, autoantibody levels, and electrophysiological studies) were performed whenever necessary.

Identification of the most symptomatic stenosis considering the potential for the disease to progress postoperatively was challenging. In general, lumbar surgery was performed first (Group A) if there were significant neurological signs in the lower limbs compared to the upper limbs, and cervical surgery was performed first (Group B) if there were upper motor neuron signs or predominant neurological signs in the upper extremities.

All surgeries were performed by the same orthopedic spine surgery team. Surgical procedures for cervical stenosis were anterior cervical discectomy and fusion (ACDF), or posterior laminoplasty using Hirabayashi's method. Surgical procedures for lumbar stenosis were laminectomy with or without posterior stabilization and fusion.

During the postoperative period, patients were monitored closely with attention to symptoms pertaining to the nonoperated stenosis, as well as complications to the operative site such as symptomatic hematoma, wound-related problems, and residual or recurrent stenosis. Patients were regularly followed-up on a yearly basis for at least 2 years, and their functional outcomes were analyzed using mJOA score and Nurick's grading. A second surgery was performed only when conservative management failed to mitigate symptoms of the non-operated stenosis.

Statistical analyses were performed using IBM SPSS version 20.0 (IBM Corp., Armonk, NY, USA). Comparisons of continuous variables were done using Student's $t$-test and Mann-Whitney $U$ test, as appropriate, and the Chi-Square test and Fisher's exact test, as appropriate for categorical 
variables. Standard Kaplan-Meier survival curves were used to examine the time to a second-stage surgery as a predefined study end point. The log-rank test was used to compare Kaplan-Meier curves in stratified survival analysis. Multivariate logistic regression was employed for each potential risk factor (binary coded) for risk of a second-stage surgery. Odds ratios (ORs) and 95\% confidence intervals (CIs) were estimated and tested using the Wald $\chi^{2}$ test. Parameters with sufficient discriminatory power $(p<0.10)$ were then examined for mutual correlation, and interaction terms were coded for significantly correlated pairs of variables. The final set of potential prognostic factors and interaction terms (all binary code) was subjected to a backward stepwise selection algorithm in the multivariate logistic regression. A $p$ value of $<0.05$ was considered statistically significant in all univariate and multivariate analyses.

\section{Results}

Eighty-four patients had surgery for symptomatic TSS during the study period. After excluding patients who did not satisfy the inclusion criteria, a total of 47 patients were included in the analysis. Based on the surgical priority, they were divided into Group A (lumbar first; $n=11$ ) and Group B (cervical first; $n=36$ ). Group A was followed-up for an average of 36.7 months, and Group B for an average of 35.0 months. The preoperative mJOA score of Group A (12.5) and Group B (11.2) were comparable $(p=0.06)$. However, the preoperative Nurick's grade of Group B (3.2) was significantly higher than that of Group A (2.3) $(p=0.003)$. Eight (72.2\%) patients in Group A and 31 (86.1\%) patients in Group B had grade 3 cervical stenosis, and five patients (45.5\%) in Group A and 12 patients (33.3\%) in Group B had grade 3 lumbar stenosis. There were no significant differences in demographic characteristics between the two groups except for Nurick's grade (Table 1).

After the primary surgery, one patient (9\%) in Group A and 25 patients (69\%) in Group B had complete resolution of symptoms during their follow-up. All of these patients had significant improvement at 1-year postoperative follow-up, as compared to preoperatively. There were no intraoperative complications such as incidental durotomy or implant malposition, and no postoperative complications such as woundrelated problems, or the occurrence of new neurologic deficits including cauda equina syndrome or compression due to epidural hematoma.

Symptom progression related to the non-operated region is summarized in Table 2. Eight patients (73\%) in Group A developed new symptoms due to cervical stenosis after an interval of $4.8 \pm 6.25$ months (Fig. 1). Of these patients, three developed cervical radiculopathy, five myelopathy, and one both cervical radiculopathy and myelopathy. In
Table 1 Demographic data

\begin{tabular}{llll}
\hline & Group A $(n=11)$ & Group B $(n=36)$ & $p$ value \\
\hline Age & $60.0 \pm 12.68$ years & $58.7 \pm 8.47$ years & 0.70 \\
Male sex & $7(64 \%)$ & $30(83 \%)$ & 0.16 \\
Follow-up duration & 36.7 months & 35.0 months & 0.79 \\
mJOA score & 12.5 & 11.2 & 0.06 \\
Nurick's grade & 2.3 & 3.2 & $0.003^{*}$ \\
MRI stenosis grade & & & 0.64 \\
$\quad$ cervical-lumbar) & & & \\
3-3 & 3 & 10 & \\
3-2 & 2 & 10 & \\
3-1 & 3 & 11 & \\
2-3 & 1 & 2 & \\
2-2 & 1 & 2 & 0.16 \\
2-1 & 0 & 1 & \\
1-3 & 1 & 0 & \\
Cervical grade 3 & $8(72.7 \%)$ & $31(86.1 \%)$ & \\
$\quad$ stenosis & & & \\
Lumbar grade 3 & $5(45.5 \%)$ & & \\
stenosis & & & \\
\hline
\end{tabular}

The groups were statistically similar, except for Nurick's grade mJOA modified Japanese Orthopaedic Association, MRI magnetic resonance imaging

*Statistically significant

Table 2 Progression of symptoms due to the non-operated stenosis

\begin{tabular}{|c|c|c|c|}
\hline & $\begin{array}{l}\text { Group A } \\
(n=11)\end{array}$ & $\begin{array}{l}\text { Group B } \\
(n=36)\end{array}$ & $p$ value \\
\hline Single symptomatic TSS & 9 & 18 & \\
\hline No new symptoms & 1 & 10 & \\
\hline Newly developed symptoms ${ }^{\mathrm{a}}$ & 8 & 8 & \\
\hline $\begin{array}{l}\text { Duration to new symptoms } \\
\text { (month) }\end{array}$ & $4.8 \pm 6.25$ & $18.8 \pm 16.82$ & 0.55 \\
\hline Requiring second-stage surgery & 8 & 2 & \\
\hline $\begin{array}{l}\text { Interval between surgeries } \\
\text { (month) }\end{array}$ & $8.0 \pm 5.61$ & $11.2 \pm 1.77$ & 0.47 \\
\hline Coexisting symptomatic TSS & 2 & 18 & \\
\hline Improvement of symptoms & 0 & 9 & \\
\hline $\begin{array}{l}\text { No improvement, but exacerba- } \\
\text { tion requiring second-stage } \\
\text { surgery }\end{array}$ & 2 & 9 & \\
\hline $\begin{array}{l}\text { Interval between surgeries } \\
\text { (month) }\end{array}$ & $1.1 \pm 0.49$ & $5.7 \pm 2.40$ & 0.002 \\
\hline $\begin{array}{l}\text { Total number of second-stage sur- } \\
\text { geries for non-operated stenosis } \\
\text { (percentage) }\end{array}$ & $10(91 \%)$ & $11(31 \%)$ & $<0.001$ \\
\hline $\begin{array}{l}\text { Interval between surgeries } \\
\text { (month) }\end{array}$ & $6.6 \pm 5.77$ & $7.9 \pm 6.42$ & 0.64 \\
\hline
\end{tabular}

TSS tandem spinal stenosis

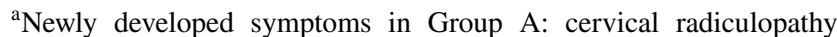
$(n=3)$, myelopathy $(n=6)$; newly developed symptoms in Group B: lower back pain $(n=6)$, leg pain or numbness $(n=6)$, neurogenic claudication $(n=7)$ 
Fig. 1 Group A patient. A 55-year-old female had lower back pain, bilateral sciatica, neurogenic claudication, and no signs in the upper extremities $(\mathrm{mJOA}$ score $=14$, Nurick's grade $=2$ ). Imaging showed cervical stenosis at levels $\mathrm{C} 4-\mathrm{C} 7$, grade 3 at $\mathrm{C} 5-6$ (a, b), and lumbar grade 2 stenosis at L4-L5 associated with degenerative spondylolisthesis (c, d). She underwent lumbar surgery first (e, f). New upper motor neuron signs including knee hyperreflexia and unsteady gait occurred 2 months after the primary surgery. A second surgery for the cervical stenosis was performed (mJOA score $=12$, Nurick's grade $=3$ ). The interval between surgeries was 7.5 months. At 2 years she had improvement in her mJOA score and Nurick's grade (mJOA score $=14$, Nurick grade $=2)(\mathbf{g}, \mathbf{h})$

addition, two patients (18\%) had exacerbations of their previous upper extremity symptoms, making the second-stage surgery absolutely necessary after a short interval of only $1.1 \pm 0.49$ months (range $0.7-1.4$ months). The symptoms of these patients resolved completely.

Eight patients (22\%) in Group B developed new symptoms due to the lumbar stenosis after an interval of $18.8 \pm 16.82$ months. Six patients developed lower back pain, six leg pain or numbness, and seven neurogenic claudication. However, only two patients required a second-stage surgery for relief. The remaining patients were treated conservatively with resolution of their symptoms (Fig. 2). Of the 18 patients in Group B with co-existing lower back symptoms and/or lower limb radiculopathy, nine had improvement and achieved a stable condition, while the other nine required lumbar surgery after an interval of $5.7 \pm 2.40$ months.

Ten patients (91\%) in Group A and 11 patients (31\%) in Group B required a second-stage surgery for the initially non-operated stenosis $(p=0.001$, statistical power: 0.99$)$. Before the second-stage surgery, Group A patients had significant worsening of mJOA score and Nurick's grade, whereas Group B patients experienced improvement of mJOA score and Nurick's grade. However, statistically significant group differences before the second-stage surgery were only noted with regard to mJOA score (Fig. 3). There were no differences between the groups in mJOA score and Nurick's grade after the second-stage surgery. The average intervals between surgeries were 6.6 months and 7.9 months for Group A and Group B, respectively.

Kaplan-Meier survival curve analysis indicated a significant difference in survival between the groups $(p<0.001)$. The requirement for a second-stage surgery in Group B was significantly less than the requirement in Group A (Fig. 4). Based on univariate analysis, factors such as allotment of patients to undergo lumbar surgery first $(p<0.001)$ and severity of lumbar stenosis in Group B $(p=0.02)$ were to found to be risk factors for a second-stage surgery (Table 3). However, multivariate analysis proved that allotting patients to Group A was found to be an independent risk factor for a second-stage surgery by multivariate analysis $(p=0.009$, OR 30.05, 95\% CI 2.323-388.629) (Table 4).
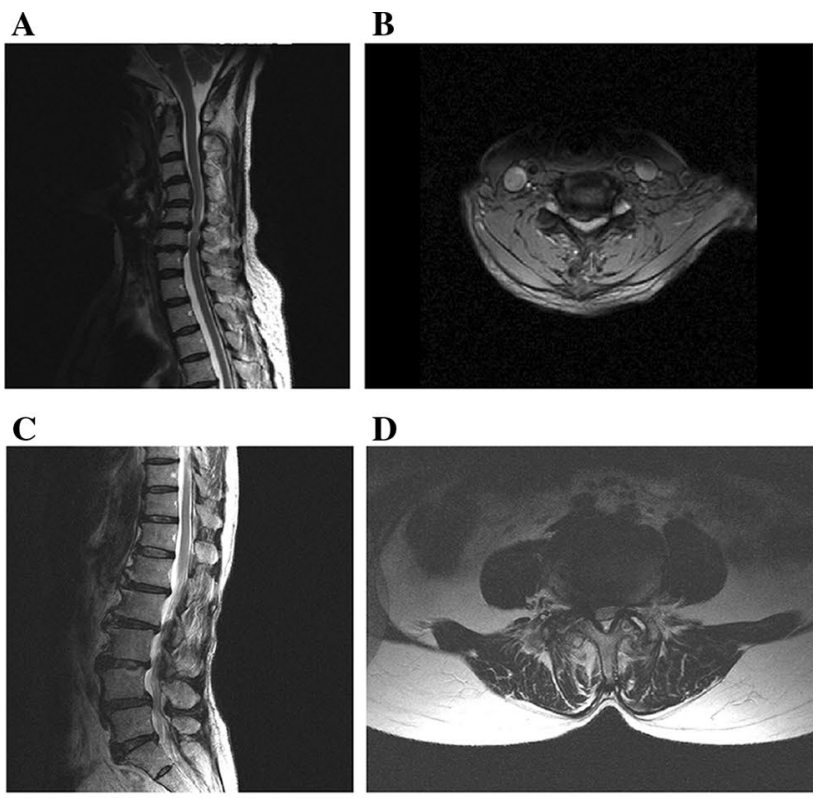

D

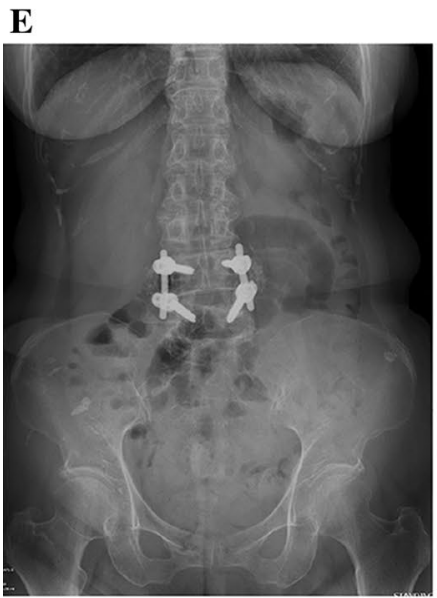

G

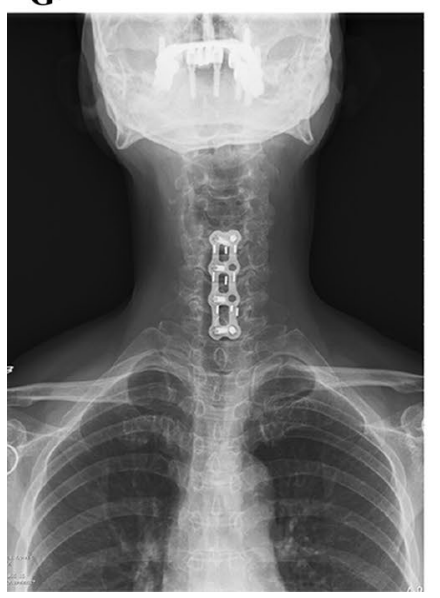

F

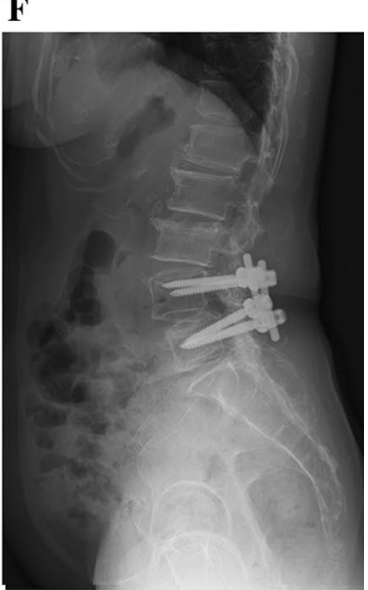

H

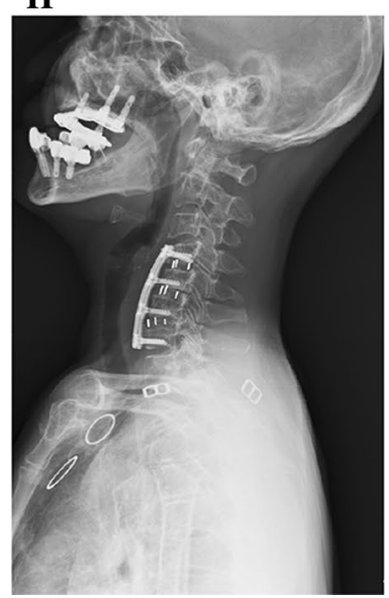

There was one wound-related complication which occurred after the second-stage lumbar surgery for a patient in Group B. Two patients in Group A and one patient in Group B developed recurrent stenosis after the second-stage 


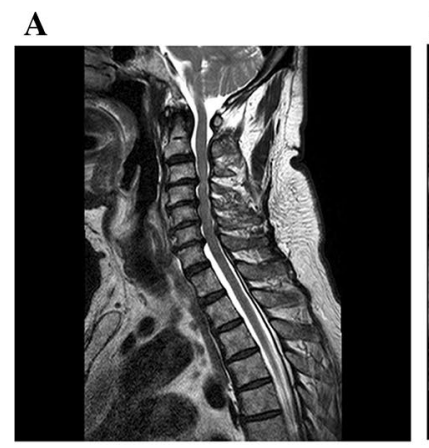

B

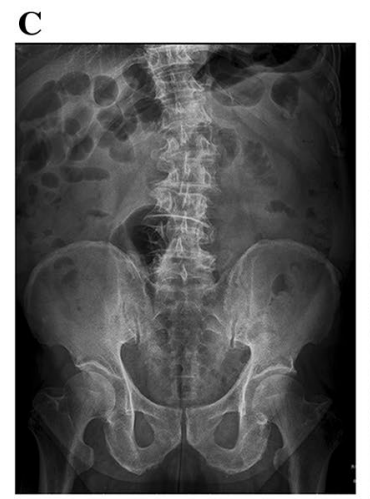

D
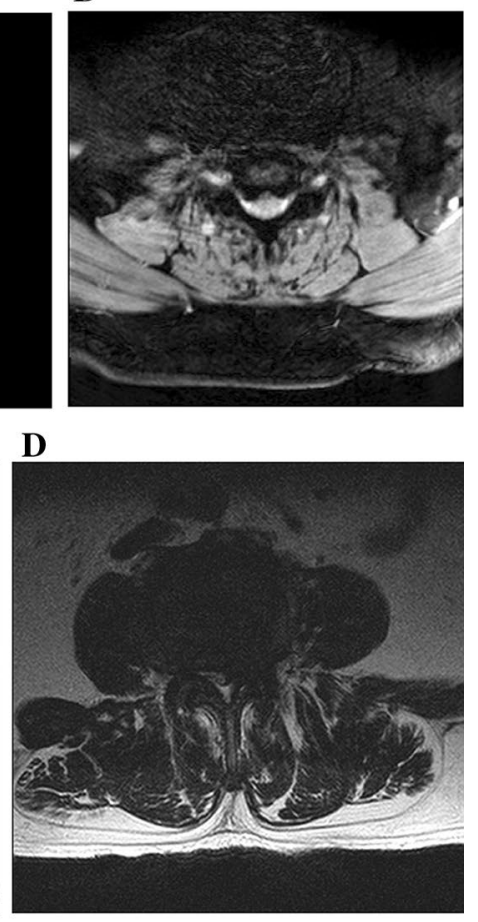

$\mathbf{E}$

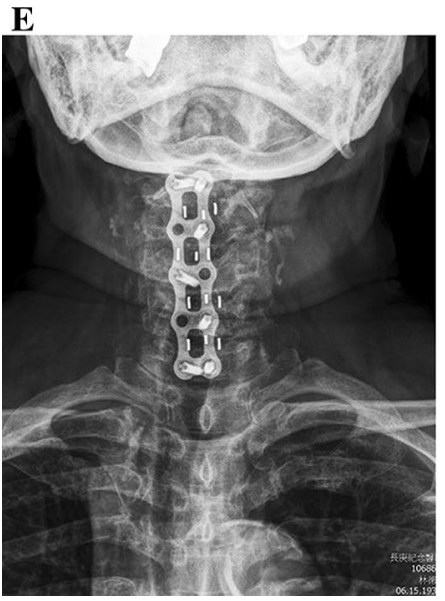

$\mathbf{F}$

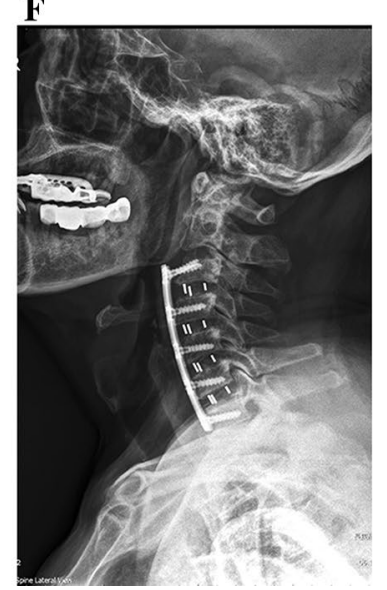

Fig. 2 Group B patient. A 74-year-old male had neck pain, a clumsy hand, and spastic gait, and no lower back or leg pain (mJOA score $=13$, Nurick's grade $=4$ ). Imaging showed grade 3cervical stenosis at C3-C7 (a, b), and grade 3 lumbar stenosis at L3-L5 associated with degenerative scoliosis $(\mathbf{c}, \mathbf{d})$. He underwent cervical surgery first $(\mathbf{e}, \mathbf{f})$, with subsequent symptom relief and stable gait (mJOA score $=15$, Nurick's grade $=2$ ). Despite new lower back pain and numbness in both legs at 2 years after the primary surgery (mJOA score $=16$, Nurick's grade $=2$ ), he had no second stage-surgery over 2.5 years of follow-up

surgery, which required an additional surgical intervention. Two patients in Group A and three patients in Group B developed adjacent segment degeneration during mid-term follow- up.

\section{Discussion}

Although the surgical management and outcomes of TSS have been reported in the literature $[1,3,5-8,10-12,18$, $19]$, to the best of our knowledge this study is the first to report the early (3-year) results of a "first stage alone" strategy in a moderate number of patients with short-term follow-up after TSS surgery.

Sixty-nine percent of the patients who had TSS with more symptomatic cervical stenosis compared to lumbar stenosis and received cervical decompression first, benefited from surgery. These results were solely on management of their cervical stenosis; they did not need a second-stage surgery for the lumbar stenosis even after an average follow-up of 35.0 months. The mJOA score and Nurick's grade improved over the first postoperative year and remained constant during the second follow-up year, despite the fact that $20 \%$ of the patients had radiological grade 3 lumbar canal stenosis.

The feasibility of withholding the second-stage surgery has been reported in the literature. Tsutsuminoto et al. [18] recommended against routine lumbar decompression for latent lumbar canal stenosis when treating TSS. Hsieh et al. [10] found that $50 \%$ of patients did not need further lumbar decompression surgery when cervical stenosis was treated first. Therefore, in select TSS patients with more symptomatic cervical stenosis, surgical management of the cervical pathology first can possibly result in resolution of lumbar stenosis symptoms over time [9].

In contrast, if the lumbar stenosis is treated first, a dramatic exacerbation of cervical stenosis-related symptoms can occur in a short interval, especially in patients with preexisting signs of cervical stenosis. In our study, $73 \%$ of patients in Group A developed new symptoms, including cervical radiculopathy or myelopathy, after an interval of $4.8 \pm 6.25$ months, while only $22 \%$ in Group B developed new symptoms of lower back pain, leg pain, or neurogenic claudication after a much longer interval of $18.8 \pm 16.82$ months. However, allotting patient into Group A (significant symptoms in the lower extremities and mild signs in the cervical region) turned out to be an independent risk factor (OR for Group $A=30.05$ ) for needing a secondstage surgery.

The pathophysiology of symptom aggravation is multifactorial and complicated. First, hyperextension positioning or accidental hyperextension during anesthesia for lumbar spinal surgery has been reported to cause devastating neurological deficits in patients with cervical stenosis [19-21]. Second, due to the natural course of the stenosis, $5-8 \%$ of patients with symptomatic lumbar stenosis and asymptomatic cervical stenosis will develop myelopathy per year [19, 22, 23]. In contrast, 3-5\% of patients with asymptomatic lumbar stenosis and cervical myelopathy will develop 


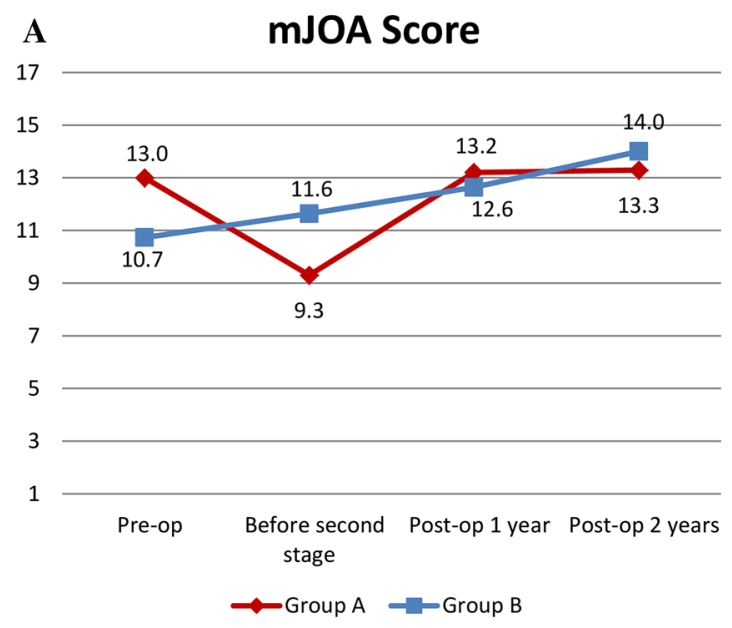

Fig. 3 Functional scores of patients requiring a second-stage operation. Significant worsening of mJOA score (a) and Nurick's grade (b) after the primary surgery and before the second-stage surgery was

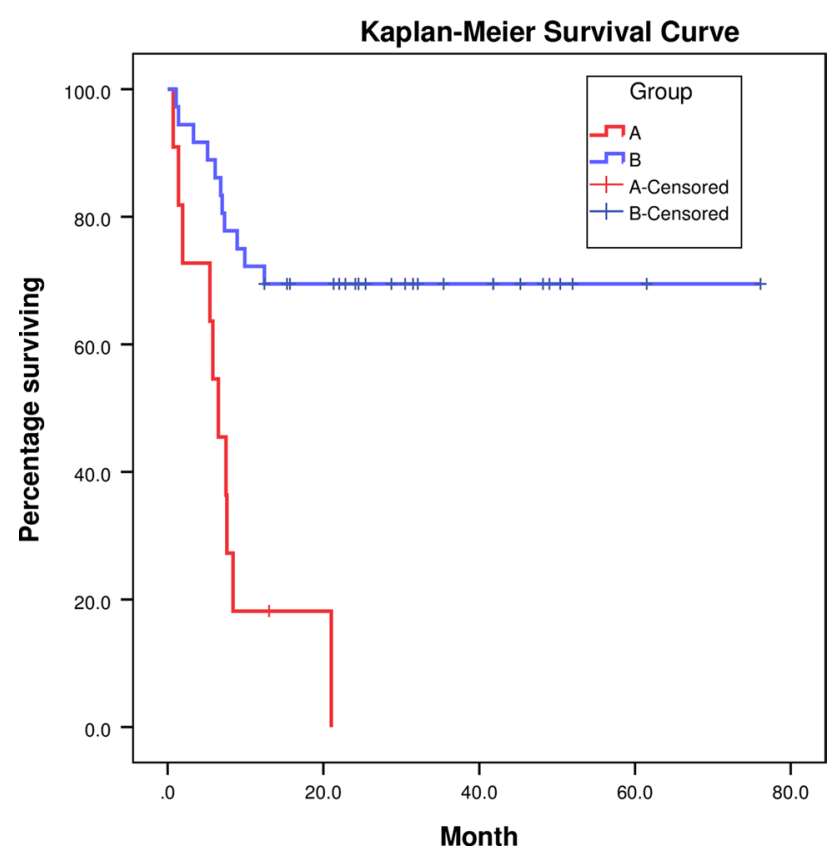

Fig. 4 Kaplan-Meier survival curves. The need for a secondstage surgery for the non-operated stenosis was significantly higher $(p=0.001)$ among patients in Group A

lower limb symptoms per year [18]. Third, symptoms usually thought to be due to lower back problems such as leg pain associated with weakness and sensory deficits may be due to myelopathy $[5,7,11,12]$.

Based on MRI evaluation, grade 3 cervical stenosis (with T2 hyperintensity) was the predominant $(72.7 \%)$ finding among Group A patients. Although grade 3 cervical stenosis represents worsening disease and the potential for

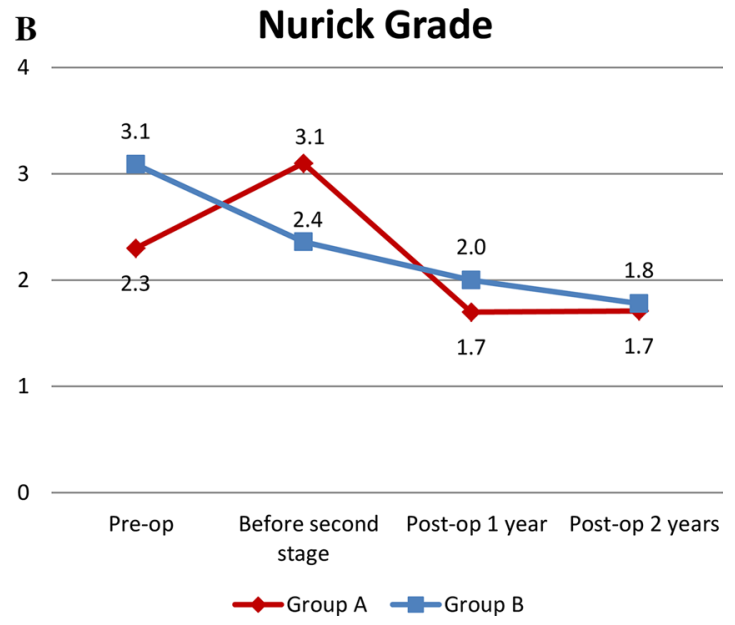

noted in Group A. Improvement of both was noted after the secondstage surgery in Group A. On the other hand, data showed staged improvement after surgeries in Group B

poor outcomes [24], Bednarik et al. [23] found no relation between grade and the development of clinically symptomatic cervical myelopathy. Ghobrial et al. [19] concluded that there is insufficient evidence in the literature to justify preemptive cervical decompression for risk reduction in patients with spinal cord injury. However, a definite answer is unavailable for why asymptomatic cervical stenosis later becomes symptomatic after the lumbar surgery in patients with TSS. This is likely because there are only a few reports in the literature that have examined a "first stage alone" strategy that treated lumbar stenosis first in patients with TSS. If lumbar surgery is done first, it is very important to be vigilant of deterioration due to the cervical stenosis. In our opinion, adopting a cervical stenosis-first strategy is more appropriate [1,8].

Our study had several limitations including its retrospective nature and non-randomized model. However, due to the high complexity and variability in the severity of stenosis and neurological status of patients with TSS, our treatment strategy was reasonable based on the available literature [1, $8,10]$. Moreover, we did not consider T1 signal change in combination with $\mathrm{T} 2$ hyperintensity, which could have been of use to predict a poor prognosis [25]. Although the number of patients requiring second-stage surgery among Group B was significantly lower than that in Group A, there are two main limitations associated with the finding. (1) The number of patients in Group A was small. (2) The follow-up period was relatively short, as it is possible that symptoms due to lumbar stenosis may occur many years after a diagnosis of lumbar stenosis. However, we believe that our finding of rapid exacerbation of symptoms related to cervical stenosis among Group A patients is highly reliable because it occurred within a relatively short time after lumbar surgery. 
Table 3 Characteristics of patients by univariate analysis

\begin{tabular}{llll}
\hline & $\begin{array}{l}\text { Surgery for the most symp- } \\
\text { tomatic stenosis }(n=26)\end{array}$ & $\begin{array}{l}\text { Surgery for both com- } \\
\text { ponents of TSS }(n=21)\end{array}$ & $p$ value \\
\hline Group A & $1(3.8 \%)$ & $10(47.6 \%)$ & $<0.001^{*}$ \\
Group B & $25(96.2 \%)$ & $11(52.4 \%)$ & \\
Age (year) & $60.0 \pm 8.81$ & $57.81 \pm 10.33$ & 0.43 \\
Male sex & $21(80.8 \%)$ & $16(76.2 \%)$ & 0.70 \\
Cervical grade 3 stenosis in Group A & 0 & $8(80.0 \%)$ & 0.27 \\
Lumbar grade 3 stenosis in Group B & $5(20.0 \%)$ & $7(63.6 \%)$ & $0.02^{*}$ \\
New symptoms after primary surgery & $6(23.1 \%)$ & $10(47.6 \%)$ & 0.08 \\
mJOA score before primary surgery & $11.4 \pm 2.21$ & $11.6 \pm 1.77$ & 0.37 \\
Nurick's grade before primary surgery & $3.2 \pm 0.86$ & $2.7 \pm 1.01$ & 0.07 \\
\hline
\end{tabular}

Allotment of patients to undergo lumbar surgery first $(p<0.001)$ and severity of lumbar stenosis in Group B $(p=0.02)$ were to found to be risk factors for a second-stage surgery

mJOA modified Japanese Orthopaedic Association, TSS tandem spinal stenosis

*Statistically significant
Table 4 Characteristics of patients by multivariate analysis

\begin{tabular}{lrll}
\hline Variables & \multicolumn{1}{l}{ OR } & $95 \%$ CI & $p$ value \\
\hline Group A & 30.05 & $2.323-388.629$ & $0.009^{*}$ \\
Age & 0.93 & $0.847-1.024$ & 0.14 \\
Male sex & 3.10 & $0.339-28.242$ & 0.32 \\
New symptoms & 1.35 & $0.260-6.977$ & 0.72 \\
$\quad \begin{array}{l}\text { after primary } \\
\quad \text { surgery }\end{array}$ & & & \\
$\begin{array}{l}\text { Nurick's grade } \\
\quad \text { before primary }\end{array}$ & 0.74 & $0.317-1.741$ & 0.49 \\
$\quad$ surgery & & & \\
\hline
\end{tabular}

Allotting patients to undergo lumbar surgery first (Group A) was found to be an independent risk factor for second-stage surgery by multivariate analysis

*Statistically significant

\section{Conclusion}

Based on our results, when managing patients with TSS, surgical correction of the cervical stenosis first significantly lowers the need for a second-stage surgery for the non-operated lumbar stenosis. In contrast, if surgery for lumbar stenosis is performed first, a dramatic exacerbation of symptoms related to the cervical stenosis can occur within a short period, demanding an immediate secondstage surgery.

\section{Compliance with ethical standards}

Conflict of interest The authors declare that they have no conflict of interest.

Open Access This article is distributed under the terms of the Creative Commons Attribution 4.0 International License (http://creativeco mmons.org/licenses/by/4.0/), which permits unrestricted use, distribution, and reproduction in any medium, provided you give appropriate credit to the original author(s) and the source, provide a link to the Creative Commons license, and indicate if changes were made.

\section{References}

1. Dagi TF, Tarkington MA, Leech JJ (1987) Tandem lumbar and cervical spinal stenosis. Natural history, prognostic indices, and results after surgical decompression. J Neurosurg 66(6):842-849. https://doi.org/10.3171/jns.1987.66.6.0842

2. van Eck CF, Spina Iii NT, Lee JY (2017) A novel MRI classification system for congenital functional lumbar spinal stenosis predicts the risk for tandem cervical spinal stenosis. Eur Spine J 26(2):368-373. https://doi.org/10.1007/s00586-016-4657-3

3. Krishnan A, Dave BR, Kambar AK, Ram H (2014) Coexisting lumbar and cervical stenosis (tandem spinal stenosis): an infrequent presentation. Retrospective analysis of single-stage surgery (53 cases). Eur Spine J 23(1):64-73. https://doi.org/10.1007/ s00586-013-2868-4

4. Nagata K, Yoshimura N, Hashizume H, Ishimoto Y, Muraki S, Yamada H, Oka H, Kawaguchi H, Akune T, Tanaka S, Nakamura K, Yoshida M (2017) The prevalence of tandem spinal stenosis and its characteristics in a population-based MRI study: the Wakayama spine study. Eur Spine J 26(10):2529-2535. https:// doi.org/10.1007/s00586-017-5072-0

5. Overley SC, Kim JS, Gogel BA, Merrill RK, Hecht AC (2017) Tandem spinal stenosis: a systematic review. JBJS Rev 5(9):e2. https://doi.org/10.2106/jbjs.rvw.17.00007

6. Kikuike K, Miyamoto K, Hosoe H, Shimizu K (2009) One-staged combined cervical and lumbar decompression for patients with tandem spinal stenosis on cervical and lumbar spine: analyses of clinical outcomes with minimum 3 years follow-up. J Spinal Disord Tech 22(8):593-601. https://doi.org/10.1097/BSD.0b013 e3181929cbd

7. Eskander MS, Aubin ME, Drew JM, Eskander JP, Balsis SM, Eck J, Lapinsky AS, Connolly PJ (2011) Is there a difference between simultaneous or staged decompressions for combined cervical and lumbar stenosis? J Spinal Disord Tech 24(6):409-413. https://doi. org/10.1097/BSD.0b013e318201bf94 
8. Aydogan M, Ozturk C, Mirzanli C, Karatoprak O, Tezer M, Hamzaoglu A (2007) Treatment approach in tandem (concurrent) cervical and lumbar spinal stenosis. Acta Orthop Belg 73(2):234-237

9. Li WJ, Guo SG, Sun ZJ, Zhao Y (2015) Multilevel thoracic ossification of ligamentum flavum coexisted with/without lumbar spinal stenosis: staged surgical strategy and clinical outcomes. BMC Musculoskelet Disord 16:206. https://doi.org/10.1186/s1289 1-015-0672-5

10. Hsieh CH, Huang TJ, Hsu RW (1998) Tandem spinal stenosis: clinical diagnosis and surgical treatment. Changgeng Yi Xue Za Zhi 21(4):429-435

11. Felbaum DR, Fayed I, Stewart JJ, Sandhu FA (2016) Relief of lumbar symptoms after cervical decompression in patients with tandem spinal stenosis presenting with primarily lumbar pain. Cureus 8(12):e940. https://doi.org/10.7759/cureus.940

12. Epstein NE, Epstein JA, Carras R, Murthy VS, Hyman RA (1984) Coexisting cervical and lumbar spinal stenosis: diagnosis and management. Neurosurgery 15(4):489-496

13. Baron EM, Young WF (2007) Cervical spondylotic myelopathy: a brief review of its pathophysiology, clinical course, and diagnosis. Neurosurgery 60(1 Supp1 1):S35-S41. https://doi.org/10.1227/01. neu.0000215383.64386.82

14. Nurick S (1972) The pathogenesis of the spinal cord disorder associated with cervical spondylosis. Brain 95(1):87-100

15. Kang Y, Lee JW, Koh YH, Hur S, Kim SJ, Chai JW, Kang HS (2011) New MRI grading system for the cervical canal stenosis. AJR Am J Roentgenol 197(1):W134-W140. https://doi. org/10.2214/ajr.10.5560

16. Lee GY, Lee JW, Choi HS, Oh KJ, Kang HS (2011) A new grading system of lumbar central canal stenosis on MRI: an easy and reliable method. Skeletal Radiol 40(8):1033-1039. https://doi. org/10.1007/s00256-011-1102-x

17. Park MS, Moon SH, Kim TH, Oh JK, Lyu HD, Lee JH, Riew KD (2015) Asymptomatic stenosis in the cervical and thoracic spines of patients with symptomatic lumbar stenosis. Glob Spine J 5(5):366-371. https://doi.org/10.1055/s-0035-1549031
18. Tsutsumimoto T, Shimogata M, Yui M, Ohta H, Misawa $H$ (2012) The natural history of asymptomatic lumbar canal stenosis in patients undergoing surgery for cervical myelopathy. J Bone Jt Surg Br 94(3):378-384. https://doi. org/10.1302/0301-620x.94b3.27867

19. Ghobrial GM, Oppenlander ME, Maulucci CM, Viereck M, Prasad S, Sharan AD, Harrop JS (2014) Management of asymptomatic cervical spinal stenosis in the setting of symptomatic tandem lumbar stenosis: a review. Clin Neurol Neurosurg 124:114-118. https://doi.org/10.1016/j.clineuro.2014.06.012

20. Deem S, Shapiro HM, Marshall LF (1991) Quadriplegia in a patient with cervical spondylosis after thoracolumbar surgery in the prone position. Anesthesiology 75(3):527-528

21. Wilkes LL (1980) Paraplegia from operating position and spinal stenosis in non-spinal surgery: a case report. Clin Orthop Relat Res 146:148-149

22. Wilson JR, Barry S, Fischer DJ, Skelly AC, Arnold PM, Riew KD, Shaffrey CI, Traynelis VC, Fehlings MG (2013) Frequency, timing, and predictors of neurological dysfunction in the nonmyelopathic patient with cervical spinal cord compression, canal stenosis, and/or ossification of the posterior longitudinal ligament. Spine (Phila Pa 1976) 38(22 Suppl 1):S37-S54. https ://doi.org/10.1097/BRS.0b013e3182a7f2e7

23. Bednarik J, Kadanka Z, Dusek L, Novotny O, Surelova D, Urbanek I, Prokes B (2004) Presymptomatic spondylotic cervical cord compression. Spine (Phila Pa 1976) 29(20):2260-2269

24. Li F, Chen Z, Zhang F, Shen H, Hou T (2011) A meta-analysis showing that high signal intensity on T2-weighted MRI is associated with poor prognosis for patients with cervical spondylotic myelopathy. J Clin Neurosci 18(12):1592-1595. https://doi. org/10.1016/j.jocn.2011.04.019

25. Tetreault LA, Dettori JR, Wilson JR, Singh A, Nouri A, Fehlings MG, Brodt ED, Jacobs WB (2013) Systematic review of magnetic resonance imaging characteristics that affect treatment decision making and predict clinical outcome in patients with cervical spondylotic myelopathy. Spine (Phila Pa 1976) 38(22 Suppl 1):89-110. https://doi.org/10.1097/BRS.0b013e3182a7eae0

\title{
Affiliations
}

\author{
Chi-An Luo ${ }^{1}$ Arun-Kumar Kaliya-Perumal ${ }^{1,2} \cdot$ Meng-Ling Lü ${ }^{3}$ Lih-Huei Chen ${ }^{1} \cdot$ Wen-Jer Chen ${ }^{1,4} \cdot$ Chi-Chien Niu $^{1}$ (b) \\ Chi-An Luo \\ j5555yrre@gmail.com \\ Arun-Kumar Kaliya-Perumal \\ dr.arunkumar.orth@gmail.com \\ Meng-Ling Lu \\ lumengling@gmail.com \\ Lih-Huei Chen \\ lhchen213216@gmail.com \\ Wen-Jer Chen \\ wenjchen4012@gmail.com \\ Linkou, Chang Gung University College of Medicine, No. 5, \\ Fusing Street, Gueishan, Taoyuan 333, Taiwan \\ 2 Department of Orthopaedic Surgery, Melmaruvathur \\ Adhiparasakthi Institute of Medical Sciences and Research, \\ Affiliated to the Tamil Nadu Dr. MGR Medical University, \\ Chennai, Tamil Nadu, India \\ 3 Department of Orthopaedic Surgery, Spine Section, Chang \\ Gung Memorial Hospital, Kaohsiung 833, Taiwan \\ 4 Department of Orthopaedic Surgery, Chung Shan Hospital, \\ Taipei 106, Taiwan
}

1 Department of Orthopaedic Surgery, Spine Section, Bone and Joint Research Center, Chang Gung Memorial Hospital, 